\title{
Description of the development of the attachment and copulatory apparatus of Dactylogyrus extensus from Cyprinus carpio var. koi
}

\author{
E. DZIKA ${ }^{1}$, M. DZIKOWIEC ${ }^{2}$, R. W. HOFFMANN ${ }^{3}$ \\ ${ }^{1}$ University of Warmia and Mazury, Faculty of Biology, Division of Zoology, ul. Oczapowskiego 5, 10-957 Olsztyn, \\ Poland, E-mail: e.dzika@uwm.edu.pl; ${ }^{2}$ Faculty of Medical Science, Division of Medical Biology, \\ Żołnierska street 14a, 10-561 Olsztyn, ${ }^{3}$ Clinic for Fish and Reptiles, University of Munich, \\ Kaulbachstr. 37, 80-539 Munich, Germany
}

\begin{abstract}
Summary
In July 2005 a Koi carp from a private pond in Bavaria was investigated. The aim of the presently reported study was to determine the composition of the monogenean fauna of Koi carp, Cyprinus carpio var. koi and to observe the development of Dactylogyrus extensus, under natural conditions, on the fish gills. A total of three species were recovered, namely: Dactylogyrus extensus Müller et Van Cleave, 1932, Dactylogyrus minutus Kulwieć, 1927, and Gyrodactylus cyprini Diarova, 1964. The dominant species was $D$. extensus, while the remaining monogeneans were not abundant. Six developmental stages of $D$. extensus were defined and they were compared with those previously observed by Prost (1963), under experimental conditions. The differences observed in size of the sclerotised structures of the haptor and the copulatory apparatus were discussed.
\end{abstract}

Keywords: Cyprinus carpio; Koi carp; monogenea; development; Dactylogyrus extensus; Germany

\section{Introduction}

The monogenean fauna of carp in commercial fishponds near Lausitz and in Wolzig Lake, situated South-West of Berlin was studied by Lux $(1987,1990)$. He found 4 species of Dactylogyrus (D. extensus, D. vastator, D. minutus and D. anchoratus) and 7 species of Gyrodactylus ( $G$. stankovici, G. kherulensis, G. shulmani, G. sprostonae, G. khatarinieri, G. cyprini, and G. medius). Kappe (2004) studied Monogenea in commercial carp ponds near Leipzig and he found 3 species of Dactylogyrus (D. vastator, D. extensus, and $D$. anchoratus). No data on the monogenean fauna of carp from Bavaria are available. Fragmentary studies on postembryonic development of $D$. extensus were carried out, under laboratory conditions, by Bauer (1951, 1959) and Bauer \& Nikolskaja (1954), but no illustrations of the developmental stages were provided. Prost (1963) studied the development and pathogenicity of $D$. extensus on carp, under experimental conditions. She also monitored the development of the sclerotised structures of the haptor and the copulatory apparatus.

The aim of the present study was to determine the specific composition of the monogenean fauna of a Koi carp $(C y$ prinus carpio var. $k o i$ ) from a private fish pond in Bavaria and to observe the development of $D$. extensus, under natural conditions, providing measurements of sequential developmental stages, including sclerotised structures of the haptor and the copulatory apparatus. These are the first studies of this kind, concerning Monogenea from Koi carp.

\section{Materials and methods}

The host fish came from a private hobby pond in Bavaria, its volume was about $25 \mathrm{~m}^{3}$, containing about 12 koi carp, length between $20-45 \mathrm{~cm}$ long. The fish was transported to the laboratory, immediately after death. At this time the water temperature was about $22{ }^{\circ} \mathrm{C}$. The fish $(5$ years of age, total length $43 \mathrm{~cm}$, total weight $1180 \mathrm{~g}$ ) was necropsied on 12 July 2005. The gills from one side and all fins were dissected. The parasites collected were fixed and preserved in GAP (Malmberg, 1970). The sclerotised structures of the attachment apparatus and the copulatory apparatus were measured and photographed under an Olympus compound (light) microscope, using the phase contrast and the Multiscan v. 4.2 image processing software. The monogenean species found were determined based on their sclerotised structures, i.e., the haptor and the copulatory apparatus - following Gusev (1985; Moravec 2004).

\section{Results}

The bacteriological and virological examinations were negative. At necropsy, massive mucus aggregation was 

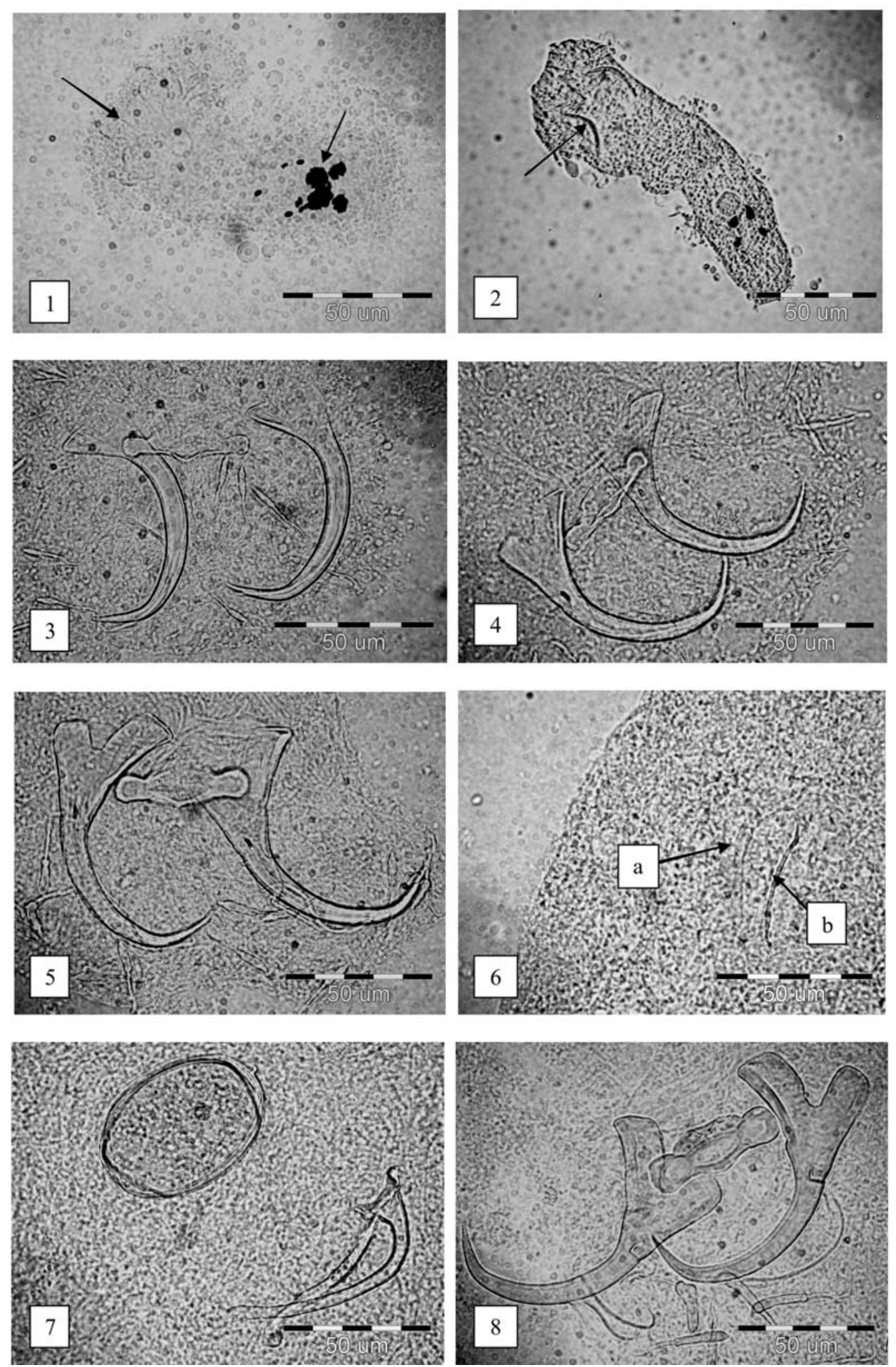

Figs. 1. Dactylogyrus extensus; oncomiracidium with eyes and marginal hooks (arrows) (stage I): scale bar $50 \mu \mathrm{m}$

Fig. 2. Dactylogyrus extensus; juvenile specimen with point of anchors (arrow) (stage II): scale bar $50 \mu \mathrm{m}$

Fig. 3. Dactylogyrus extensus; juvenile specimen with anchors without processes and with loose dorsal bar (stage III): scale bar $50 \mu \mathrm{m}$

Fig. 4. Dactylogyrus extensus; juvenile specimen with small processes and dorsal bar (stage IV): scale bar $50 \mu \mathrm{m}$

Fig. 5. Dactylogyrus extensus; juvenile specimen with longer processes and connected dorsal bar (stage IV): scale bar $50 \mu \mathrm{m}$

Fig. 6. Dactylogyrus extensus; juvenile specimen with copulatory apparatus, a - cirrus tube, b - cirrus accessory (arrows) (stage V): scale bar $50 \mu \mathrm{m}$

Fig. 7. Dactylogyrus extensus; adult specimens with eggs and fully developed copulatory apparatus (stage VI): scale bar $50 \mu \mathrm{m}$

Fig. 8. Dactylogyrus extensus; adult; anchors with fully developed inner and outer processes and dorsal bar (stage VI): scale bar $50 \mu \mathrm{m}$ 
found on gills, showing the beginning of destruction. Microscopically massive invasion by Ichthyophthyrius and monogeneans was found. A total of 873 speciemens of monogeneans were collected. The infection intensity on a single gill arch almost reached 400 individuals. The genus Dactylogyrus was represented by 2 species: D. extensus (847 specimens) (Fig. $1-8)$ and D. minutus (8 specimens) (Fig. 9, 10). These two Dactylogyrus species differs in shape and size of anchors, dorsal bar and copulatory apparatus. The third species found was Gyrodactylus cyprini (18 specimens) (Fig. 11). Of all Gyrodactylus species previously described on carp, only $G$. cyprini has an oval plate belonging to anchors. All Dactylogyrus individuals were found on the gills, while Gyrodactylus preferred the fins.

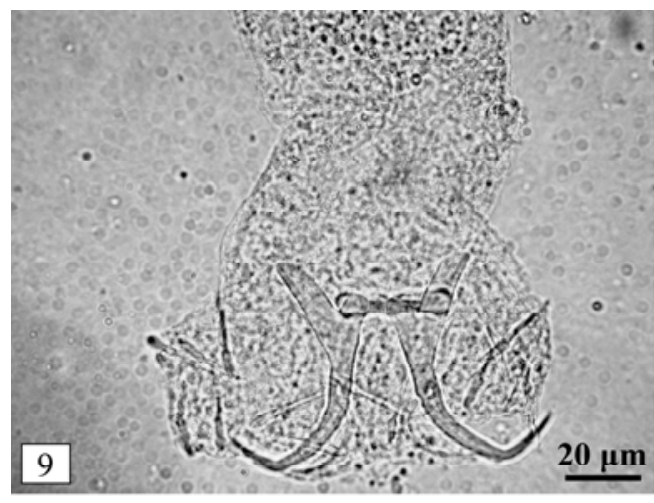

V - juvenile specimen with copulatory apparatus - 112/ $13.2 \%$ (Fig. 6). The most prevalent was stage VI - adult specimens with fully developed anchors, dorsal bar and copulatory apparatus - 555/ 65.5\% (Fig. 7, 8) were found. The measurements of the sclerotised structures are presented in Table 1.

\section{Discussion}

Comparing the parasitic fauna of the presently studied Koi carp with the parasite fauna reported from carp by other authors, it is evident that there are differences in their specific composition. The smaller number of the monogenean species found on Koi carp was probably related to the fact

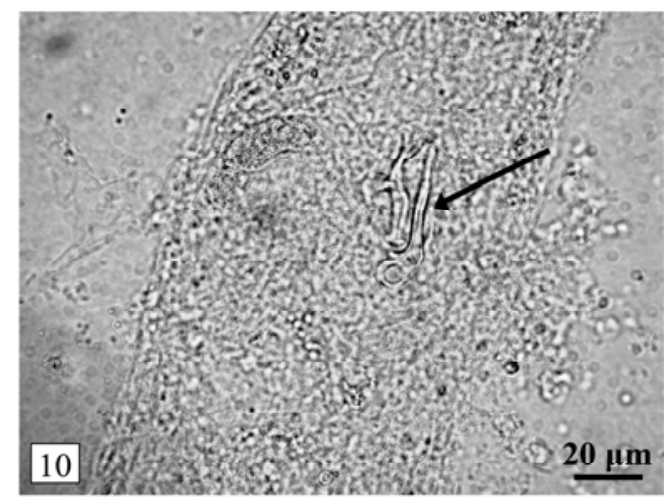

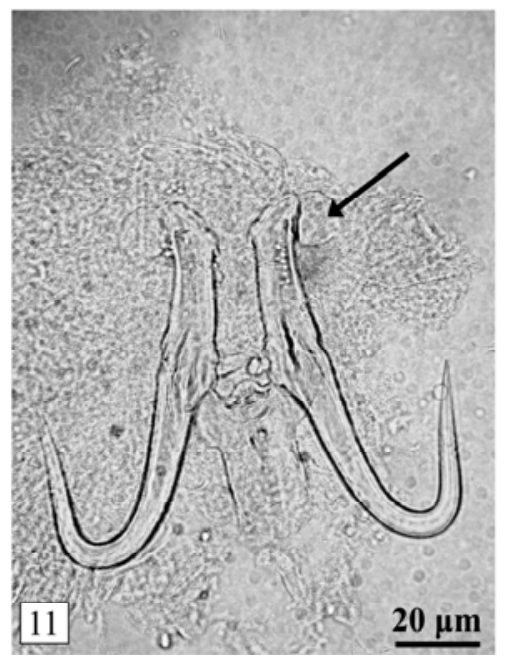

Fig. 9. Dactylogyrus minutus; haptor: scale bar $20 \mu \mathrm{m}$

Fig. 10. Dactylogyrus minutus; copulatory apparatus (arrow): scale bar $20 \mu \mathrm{m}$

Fig. 11. Gyrodactylus cyprini - haptor - anchors with oval plate (arrow): scale bar $20 \mu \mathrm{m}$

Development of D. extensus under natural conditions

Six developmental stages, in the life cycle of D. extensus, were defined by Prost (1963). All the stages (I - VI), from oncomiracidium (I) to the adult stage (VI) were found on the gills of the fish. The stage I - oncomiracidium with eyes and marginal hooks (Fig. 1) represented 13 specimens (1.5\%), stage II - juvenile specimen with point of anchors - 26/ $3.1 \%$ (Fig. 2), stage III - juvenile specimen with anchors without processes and with loose dorsal bar - 73/ $8.6 \%$ (Fig. 3), stage IV - juvenile specimen with small and longer processes and dorsal bar 68/8.1\% (Fig. 4, 5), stage that this study was based only on a single fish, whereas the data of other authors were based on multiple host fishes. Furthermore, in a small pond with only a few fish individuals, only a few parasite species can be present. Moreover, the structure of parasite communities depends on the local conditions and the number of species in a defined ecosystem is always lower than the number of parasite species recorded within the species range (Kennedy \& Guegan, 1994). In our study D. extensus was the dominant species. Paperna (1994a) showed under experimental conditions, that $D$. vastator excluded $D$. extensus. However, in 


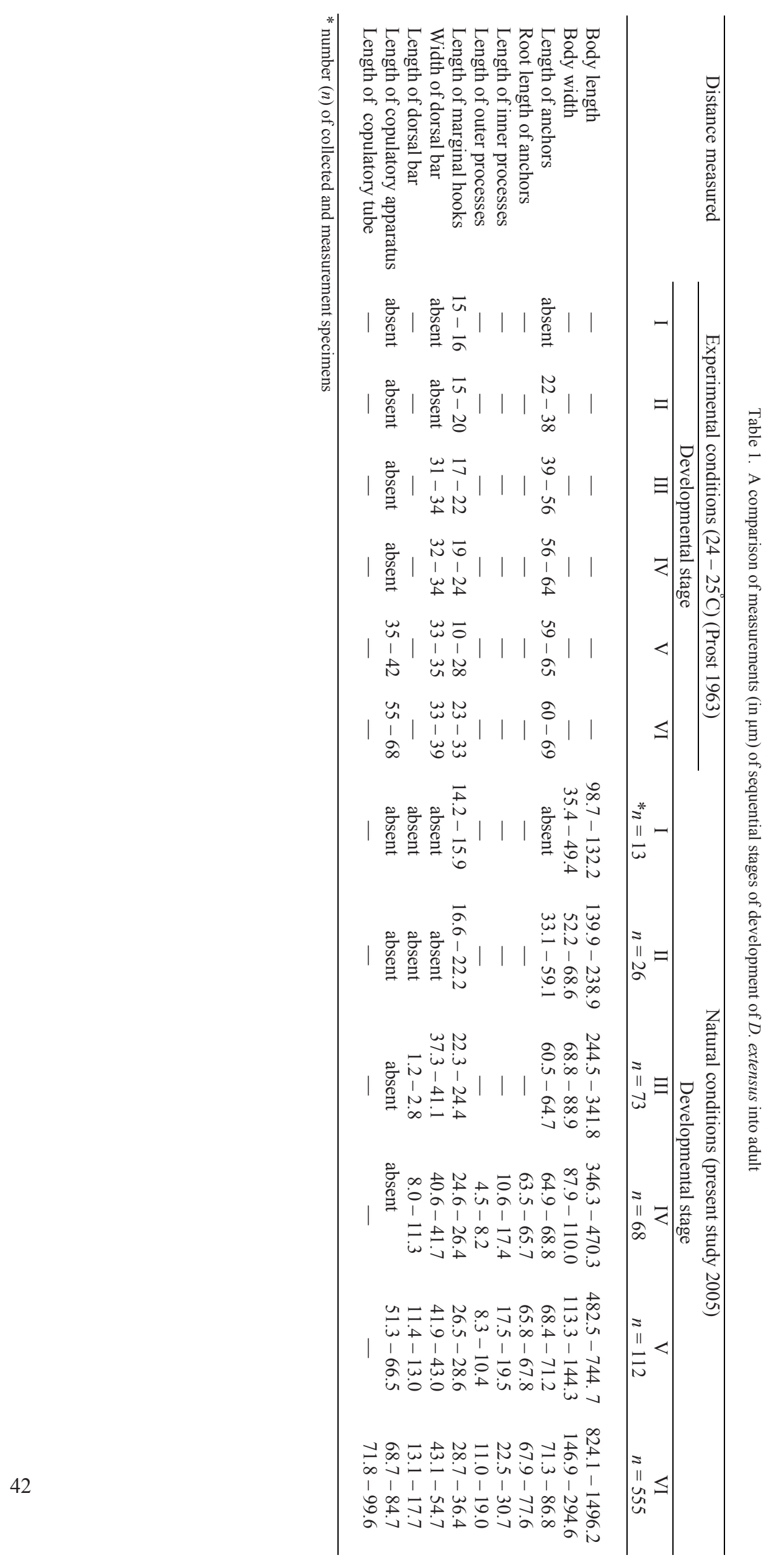


the study of Pojmańska (1995) D. extensus and D. vastator were recorded together in carp from fish ponds in Zabieniec. She concluded that perhaps low intensity of occurrence of both species is the reason for lack of competition between them. Additionally, environmental conditions may be of influence. Paperna (1964b) described adaption of $D$. extensus infecting carp reared in artificial ponds in Israel to temperature between 24 and $28{ }^{\circ} \mathrm{C}$ under experimentally controlled conditions. He concluded that the behaviour $D$. extensus under different temperature and oxygen tensions in Israel may indicate a relatively rapid effect of natural selection and the establishment of a strain of $D$. extensus well adjusted to local ecological conditions. Our study may confirm these results of Paperna. Thus, the host immune response could be involved in interaction between the two species, and this factor is clearly temperature dependent. A possibile competition between $D$. extensus and D. minutus could not be excluded, but this phenomenon should be proved under experimental conditions.

Prost (1963) studied the development and the pathogenicity of Dactylogyrus extensus on three-week-old immature carp, cultured under experimental conditions. In the present study on the development of $D$. extensus, under natural conditions on large adult fish, we observed, as did Prost (1963), that the primordial point of the anchors first appeared at stage II (Fig. 2) and the dorsal bar at stage III (Fig. 3). Stage IV marks the appearance of the processes (outer and inner) of the anchors, which enlarge at further stages of development (Figs. 4, 5). The copulatory apparatus appears at stage V (Fig. 6), while stage VI represents the adult phase (Figs. 7, 8) (Table 1). The results of measurements in this study, substantially differ from those provided by Prost (1963), regarding both the haptor and the copulatory apparatus. This could be caused by the different size of the studied fish. It is considered, that monogeneans are highly host specific in comparison to other parasitic groups of fish species (Sasal et al 1999). They also found a good relationship between host body size and parasite body size for specialist parasites. According to Šimková et al. (2001) the attachment organs are considered to be important for the determination of host specificity. On the other hand, the development of the attachment organs depends to a great extent on the host specificity. It have been established that there is correlation between host body size and the size of sclerotized parts of the haptor in case of species infecting only one host species. Dactylogyrus extensus infects exclusively the gills of the common carp. In our study was the most abundant species. In case of species with lower host specificity that sort of correlation has not been observed. However parasite living on larger hosts have to adopt their hooking system to gill filament diameter in they do not want to be removed by their host. Our results support the study Karaivanova et al (2003) who showed the presence of positive relationship between the host body size and two morphometric characters of anchors of the haptor of $D$. extensus on carp in a natural reservoir. This may be due to the necessity of more steadily attachment of parasites to hosts with a more active way of life.

\section{Acknowledgments}

This work was supported by DAAD scholarship, Germany. We thank prof. Walter Boeger for helpful comments on an earlier draft of this manuscript.

\section{References}

BAUER, O. N. (1951): A question about pathogenicity Dactylogyrus solidus Achmerov. Doklady AN SSSR 78, 4: 825 - 827 (In Russian)

BAUER, O. N. (1959): Ecology of freshwater parasites. Izv Gos Nauč Issled Instituta Ozern i Rečn Hoz 49: 1 - 206 (In Russian)

Bauer, O. N., NikOlskajA, N. P. (1954): Dactylogyrs solidus Achm., its biology, development and economic significance. Tr Problemnych $i$ Tematičeskih Soveŝčanii Zool Inst AN SSSR, 4: 99 - 109 (In Russian)

GuseV, A. V. (1985): Keys to Parasites of Freshwater Fish of the USSR. Vol 2. Parasitic Metazoa. Nauka, Leningrad (In Russian)

Karaivanova, E., Nedeva, I., Atanassov, G. (2003): Analyses of the influence of the host body size on the morphometrical characters of Dactylogyrus extensus (Mueller et van Cleave, 1932). Proceedings of the $2^{\text {nd }}$ Congress of Ecologists of Macedonia, 6: 286 - 291

KAPPE, A. (2004): Parasitologische Untersuchungen von ein- und zweijährigen Karpfen (Cyprinus carpio) aus Teichwirtschaften des Leipziger Umlaudes während der Winterhaltung. Dissertation Veterinärmedizinische $\mathrm{Fa}$ kultät der Universität Leipzig 1 - 134

Kennedy, C.R., Guegan, J. F. (1994): Regional versus local helminth parasites richness in British freshwater fish: saturated or unsaturated parasites communities? Parasitology, 109: 175 - 195

LuX, E. (1987): Neues zum Artenbestand von Gyrodactylus in der DDR. Angewandte Parasitolology, 28: 159 - 164 LuX, E. (1990): Population dynamics and interrelationships of same Dactylogyrus and Gyrodactylus species on Cyprinus carpio. Angew. Parasitol., 31: 143-149

MalmberG, G. (1970): The excretory systems and the marginal hooks as a basis for the systematics of Gyrodactylus (Trematoda, Monogenea). Ark. Zool., 2: 11 - 235

MorAVEC, F. (2004): Metazoan parasites of salmonid fishes of Europe. Academia Praha

PAPERNA, J. (1964a): Competitive exclusion of Dactylogyrus extensus by Dactylogyrus vastator (Trematoda, Monogenea) on the gills of reared carp. J. Parasitol., 50: $94-98$

PAPERNA, J. (1964b): Adaptation of D. extensus (Mueller and Van Cleave, 1932) to Ecological conditions of Artificial Ponds in Israel. J. Parasitol., 50,1: 90 - 93

POJMAŃSKA, T. (1995): Seasonal dynamics of occurrence and reproduction of some parasites in four cyprinid fish cultured in ponds. II. Monogenea. Acta Parasitol., 40: $79-$ 84

Prost, M. (1963): Investigations on the development and pathogenicity of Dactylogyrus anchoratus (Duj., 1845) and 
D. extensus Mueller et v. Cleave, 1932 for breeding carps. Acta Parasitol. Pol., 11: 17 - 47

Sasal, P., Trouvé, S., Müller-Graf, C., Morand, S. (1999: Specificity and host predictability: a comparative analysis among monogeneans parasites of fish. J. Anim.

RECEIVED FEBRUARY 21, 2008
Ecol., 68: 437 - 444

Šimková, A., Desdevises, Y., Gelnar, M., Morand, S. (2001): Morphometric correlates of host specificity in Dactylogyrus species (Monogenea) parasites of European Cyprinid fish. Parasitology, 123: 169 - 177 